\section{Ginecologia \\ QUAL A IMPORTÂNCIA DA CIRURGIA PLÁSTICA NO PLANEJAMENTO DE INCISÕES CIRÚRGICAS EM GINECOLOGIA?}

Como a ginecologia representa importante especialidade médica cirúrgica, é fundamental que o especialista em saúde feminina tenha conhecimento adequado das incisões para o acesso às diversas afecções que têm de enfrentar no seu cotidiano. Ademais, é imprescindível o planejamento das incisões objetivando também um resultado estético final e, por conseguinte, maior satisfação das pacientes.

Assim, não raro, os ginecologistas se deparam com cicatrizes de cirurgias prévias na região pélvica, especialmente a clássica incisão pela técnica Pfanestiell, muitas delas exibindo bons resultados estéticos, porém algumas vezes denotando resultados poucos satisfatórios, como cicatrizes extensas, assimétricas, hipertróficas ou mesmo queloidianas, além da queixa desanimadora da maioria dessas mulheres'.

Por isso, da mesma forma que ocorre na cirurgia plástica, a discussão prévia com a paciente, a estimativa da localização e a extensão das cicatrizes devem sempre ser obrigatórias; devem ser considerados no planejamento fatores relacionados à preferência pessoal, como posição e adequação da incisão ao tipo de vestimenta habitualmente utilizada. Apesar da dificuldade técnica da incisão transversa supra-púbica, ela exibe melhor cicatrização do que a efetuada na região abdominal, pois a tensão cutânea, disposição das linhas de força e espessura da derme influenciam na pior evolução das cicatrizes nesta última região',2.

$\mathrm{Na}$ incisão com bisturi, o ginecologista deve fazê-la sempre sobre uma dobra natural da pele e de maneira perpendicular, com o objetivo de se evitar assimetrias entre as diferentes camadas durante o processo de síntese; o não alinhamento entre as respectivas camadas, derme superficial e profunda, pode favorecer o desenvolvimento de cicatrizes não estéticas $^{1,2}$. Por isso, é aconselhável o emprego de pontos separados, com fios não absorvíveis, bem como a aproximação da derme profunda (sutura subdérmica, com pontos não absorvíveis). Para se obter cicatrizes mais finas é interessante que se faça uma segunda camada de sutura intradérmica e a realização de pontos falsos externos com bandagens do tipo micropore, que, ao favorecerem menor tensão sobre a incisão, promovem melhor resultado estético.

Outro detalhe importante é evitar a manipulação excessiva por válvulas; não raro constatam-se lacerações das margens da incisão. Assim, é prudente avaliar a viabilidade das bordas da incisão antes do início da síntese. Caso haja lacerações ou pequenas irregularidades, é imperioso que se faça o debridamento das margens da incisão até regiões com maior integridade!.

Cabe mencionar, ainda, quando é necessária a colaboração conjunta do cirurgião plástico; assim, é aconselhável ouvir a opinião do cirurgião plástico nos casos de cirurgia ginecológica associada à cirurgia estética combinada, nos de cirurgias da glândula mamária (afecções benignas ou malignas) e naqueles de mulheres com história prévia de má cicatrização.

Nos casos de deformidades estéticas do abdômen, onde há a ressecção cutânea associada com a retirada do excesso de gordura, a via de acesso para o procedimento ginecológico deve ser planejada de acordo com a incisão a ser empregada pelo cirurgião plástico.

Na cirurgia mamária, o acesso cirúrgico apresenta também relevância, uma vez que a presença de cicatrizes mal posicionadas pode prejudicar o resultado estético final. Dessa forma, deve-se posicionar a incisão sobre regiões preferenciais como nas linhas de força naturais da mama ou em regiões anatômicas específicas. Do ponto de vista estético as incisões periareolares apresentam melhor resultado estético, quando comparadas às incisões realizadas sobre mama. Nas situações de possibilidade de reconstrução, o acesso em conjunto com a técnica de cirurgia plástica deve ser estimulado, pois além de favorecer a ampliação do campo operatório, promove melhor resultado estético final.

Nos casos de antecedentes pessoais de má cicatrização, é aconselhável o emprego imediato de técnicas de cirurgia plástica',2; assim, além dos cuidados habituais, deve ser realizada a síntese cutânea da forma mais atraumática possível e, de preferência, com fios inabsorvíveis ${ }^{3}$. No pós-operatório, a utilização de placas compressivas de silicone gel $\left.\right|^{4}$ redunda em grande benefício. Em pacientes com cicatrizes do tipo quelóide, a aplicação de corticosteróides na cicatriz e/ou betaterapia deve ser aventada ${ }^{1,2}$.

Assim, no planejamento das incisões cirúrgicas, é fundamental a técnica cirúrgica elaborada, sempre dentro de conceitos fundamentados na cirurgia plástica.

Em situações específicas, os principais benefícios auferidos pelo planejamento conjunto entre os dois profissionais incluirão não somente uma maior exposição do campo operatório, mas também maior facilidade técnica e melhor resultado estético global.

Alexandre Mendonça Munhoz Cláudia Maria Santos Aldrighi José Mendes Aldrighi

Referências

I. Mustoe TA, Cooter RD, Gold MH, Hobbs FD, Ramelet AA, Shakespeare PG, Stella M, Teot L, Wood FM, Ziegler UE. International clinical recommendations on scar management. Plast Reconstr Surg. 2002 Aug; I I 0 (2):560-7I

2.Brissett AE, Sherris DA. Scar contractures, hypertrophic scars, and keloids. Facial Plast Surg. 200 I Nov; 17(4):263-72.

3. Rudolph R. Wide spread scars, hypertrophic scars, and keloids. Clin Plast Surg. 1987 Apr; | 4(2):253-60.

4. Katz BE. Silicone gel sheeting in scar therapy. Cutis. 1995 Jul;56(I):65-7. 